Revista de la red interuniversitaria de estudios sobre las

literaturas rioplatenses contemporáneas en Francia

$9 \mid 2013$

Homenaje a Ana María Barrenechea

\title{
La crítica literaria o La costurerita que dio aquel mal paso
}

\section{Blas Matamoro}

\section{OpenEdition}

\section{Journals}

Edición electrónica

URL: http://journals.openedition.org/lirico/1096

DOI: 10.4000/lirico.1096

ISSN: 2262-8339

Editor

Réseau interuniversitaire d'étude des littératures contemporaines du Río de la Plata

\section{Referencia electrónica}

Blas Matamoro, "La crítica literaria o La costurerita que dio aquel mal paso », Cuadernos LIRICO [En línea], 9 | 2013, Puesto en línea el 01 septiembre 2013, consultado el 01 mayo 2019. URL : http:// journals.openedition.org/lirico/1096 ; DOI : 10.4000/lirico.1096

Este documento fue generado automáticamente el 1 mayo 2019.

\section{(c) $(1) \odot$}

Cuadernos LIRICO está distribuido bajo una Licencia Creative Commons Atribución-NoComercialSinDerivar 4.0 Internacional. 


\title{
La crítica literaria o La costurerita que dio aquel mal paso
}

\author{
Blas Matamoro
}

1 La costurerita aquella, en el verso de Evaristo Carriego, dio el mal paso y lo peor de todo, sin ninguna necesidad. Es la diferencia que encuentro entre ella y la crítica literaria, cuyo mal paso es necesario. En efecto, la costurerita no es la clienta que le encarga un vestido, ni el fabricante de la tela empleada, ni la autora del modelo, la modista o el modisto. No tiene siquiera el cuerpo que revestirá su obra. Sin embargo, sin ella el vestido no habrá de existir.

2 Sin el crítico, la literatura no existiría. Se me dirá que tampoco sin el escritor, el editor ni los lectores silvestres que no pretenden ejercer la crítica. Todo esto es verdad, tan verdadero que podríamos situar la almendra de la literatura en lo que, hace siglos, significaba esta palabra : lectura. Tener literatura, tener letras, era tener libros en casa, o en la biblioteca de quien fuera, o recibirlos en préstamo o robarlos y haberlos leído. Y así fue y es posible identificar la literatura con el acto de leer, para lo cual hace falta el libro y alguien con la competencia suficiente como para entender lo que allí aparece escrito o, al menos, creer que puede entenderlo. Lo que intento decir es que sin el crítico la literatura no existiría como relectura, no simplemente como lectura primaria de un texto, sino como texto de su propia lectura.

Entonces : tanto el lector silvestre que lee por afición como el crítico resabiado que lee por oficio - se supone que habiéndolo adquirido también por afición - son los que acceden a un texto en tanto literario. Al hacerlo, producen lo que estrictamente se llama literatura. De aquí algunas diferencias : la crítica se ocupa de la lectura del texto y no del texto en sí mismo que, en tanto tal, es el objeto de la lingüística, la gramática histórica o la hoy olvidada cuando no vilipendiada retórica. Estas disciplinas respetan el texto como ensimismado. La crítica, al igual que el lector de literatura, lo manipula - única manera de 
no repetirlo - y lo altera, lo convierte en propiedad de otro que estaba como mera virtualidad en él y ahora se ha realizado. Y da el mal paso de retextualizarlo, de extraer un texto de otro lo cual, si se quiere, puede considerarse una traducción, generalmente hecha dentro y no fuera de la lengua en que el texto fue escrito.

En el símil de la costura diríamos que el escritor es el modisto y el editor es el que ofrece catálogos de vestidos. Las costureritas son los lectores. Todas ellas son virtuosas, salvo el crítico, que es una costurerita viciosa porque una vez leído un texto, en lugar de incorporarlo a su memoria, como hace el lector corriente, lo convierte en objeto y discurre sobre él. Mayormente sin darse cuenta, el lector se ha puesto el vestido y se ha mirado en un espejo imaginario, comprobando qué bien o qué mal le sienta. Si se lo quita para entregarlo a su clienta, es un lector corriente. Si se lo queda, hurtándolo, para luego retocarlo, es un crítico. Bueno, puede pegar tijeretazos torpes y conseguir meros andrajos, así como mancharlo con sustancias insolubles o, lo que no es imposible, venderlo a un ropavejero. 0 , vengativamente, quemarlo. 0 mejorarlo y darlo gratis a quien tiemble de frío y necesite abrigo. La literatura, es decir la lectura, siempre tiene algo de refugio.

En esta duplicidad de discursos acerca de un mismo objeto, que es el texto, se inscribe la tarea del crítico, al que adjudico la calidad de vicio - la lectura lo es y hasta impune, como quieren algunos - porque intenta convertir un hecho único en algo universal o sea replicable, reproducible. Si respetara el acto de lectura como único, como radical y absolutamente concreto, no podría ejercer la crítica. De lo único no hay razón, dicen los filósofos, pues razonar es comparar. La vivencia que se asocia al acto de leer - tal día, a tales horas, en tal lugar, en tales otras circunstancias, todo irreproducible porque situado en la temporalidad - el lector corriente se la guarda y el crítico la trabaja. De ahí que su mal paso sea necesario. Diría más : vertiginoso porque de aquel texto y aquella lectura obtendrá otro texto que, a la vez, será leído y podrá ser criticado y así hasta el infinito, si es que tal cosa existe.

El lector corriente se guarda su lectura en la plenitud del recuerdo o la vacuidad del olvido. El crítico, en cambio, la expondrá a la consideración pública. Juzgará si ha podido entrar; si es tan admirable lo leído que se le ha resistido, como exige Paul Valéry para los buenos libros; si se ha quedado afuera porque el aburrimiento lo distanció de lo legible, tornándolo ilegible. Y, además - y aquí viene lo más peliagudo - deberá explicitar o manejar sin decirlo algún criterio que es, justamente, lo que hace de él un crítico.

\section{2}

7 Nuestro más remoto contacto con la crítica, me atrevo a decirlo, suele ser con un manual de historia literaria. Con él aprendimos que la literatura es la historia de la literatura, entendida como una tradición estructurada, formalizada. También aprendimos que se puede hablar y aun escribir sobre obras literarias sin haberlas leído, simplemente con aprender el nombre de los autores, sus vagas fechas biográficas, cuatro alfilerazos sobre sus temas preferidos y la escuela estética a la cual se lo acostumbra adscribir. Todo ello es esencialmente erróneo porque suprime el acto único de la lectura, del cual ya hice sobrada referencia. Para esta noción institucional de la literatura, es literario todo lo que aparece en sus manuales. Entonces: la literatura es la población de escritores que merecen ser estudiados por las cátedras respectivas, que han recibido algún premio, que 
suelen ser traducidos, que eventualmente, tras postrarse en la muerte, se levantan en bronces y mármoles o en el nombre de plazas y calles.

Ciertamente, la literatura así entendida tiene historia y es legítimo hacerla. Se la puede realizar teniendo en cuenta las circunstancias epocales en que se ha producido, la clase social a la que pertenecían los escritores en tales o cuales tiempos, sus relaciones buenas o malas con los poderes contemporáneos, la formación de un público y un negocio relativo a los libros, etc. En cualquier caso, faltaría en el análisis la historia de lo que venimos admitiendo como esencial en la vida de la textualidad literaria : una historia de la lectura. Haciendo jugar esta variable, la noción institucional de lo literario, que cierra las categorías con su formalización académica, se abre en tanto los libros que se siguen leyendo continúan produciendo aquella retextualización crítica ya mencionada. La historia no termina en el umbral del ministerio sino que sigue en la calle y es promesa de futuro donde, por decirlo literariamente, toda obra es inédita. Sin presencia del lector ante el texto y viceversa, vale repetirlo, no hay literatura.

9 Autores como Hans Robert Jauss, Harald Weinrich y Wolfgang Iser han trabajado en este sentido, poniendo en el centro de su búsqueda la recepción que un texto tiene en diversos lugares y épocas. Incluso hay quien habla, y no sin criterio, de una estética de la recepción, entendiendo que si bien un texto tiene sus signos, también tiene sus huecos y en ellos el lector coloca sus propios signos, a partir de las emociones que la lectura le produce pero no sólo de ellas. En esta medida, completa, aunque sea de modo parcial y provisorio, la conformación de la obra, la coescribe o, por decirlo con palabra orteguiana, colabora a la existencia del texto. Leer no es meramente recibir pasivamente un conjunto de signos que el lector cree entender, sino recomponerlo.

Esta concepción histórica de la literatura como historia comparada de sus lecturas y lectores, pareciera poner en crisis aquella de la escuela histórica pura y dura. Más bien diría yo que la complementa si se deja complementar y no enarbola jerarquías institucionales. En efecto, la escuela histórica de la crítica - que tiene un mérito relevante : historiar las costumbres literarias que se replican y transmiten en el tiempo: las tradiciones con su correspondiente autoridad - se ve obligada a considerar una unión indisoluble entre literatura y lengua, limitando el conocimiento de una literatura a quienes pueden leer sus originales.

11 Este maridaje nos remite a una cuestión mayor : la literatura como algo nacional y, por lo mismo, como parte del patrimonio cultural de una nación, asunto que revolotea como mosca estival desde que a Herder se le ocurrió, en el siglo XVIII, inventar eso de las naciones y los nacionalismos. Infinita en sus elementos, la cultura nacional es, sin embargo, siempre igual a sí misma, esencial o sea a-histórica y dotada de identidad, como el carné de identidad donde siempre tenemos los mismos nombres y los mismos números. Aquí las cosas empiezan a chirriar.

12 En efecto: si la literatura es lectura ¿qué podemos decir críticamente de la mayor parte de los libros que hemos leído, que son traducciones o modernizaciones de originales hoy poco o nada legibles? A los lectores en castellano nos hacen falta muletas para andar por el Poema de Mio Cid y nada digo de los japoneses que pretendan recorrer las aventuras de Genji contadas por la señora Murasaki.

13 Todo ello pone en cuestión las categorías identitarias que han sido joyas de familia de la escuela histórica. Por ejemplo, sin ir demasiado lejos, espigando el campo español. Allí encontraremos definiciones para todos los gustos y perfectamente contradictorias, que 
sólo coinciden en dejar fuera, por no españolas, a las obras que no encajan en los nichos respectivos. Así son españolas por ser idealistas o realistas, por tender al misticismo contemplativo o a la pugnaz actividad heroica y conquistadora, por expandirse por el mundo en el desvivir o encerrarse en el más duro ensimismamiento, por aceptar nociones foráneas de modernidad o reclamar un arcaico sesgo original, por elogiadas como acendradas o despreciadas por su africana incapacidad de europeizarse, por exaltar las grandezas imperiales o complacerse en una doliente decadencia y suma y sigue. En todo caso, estas propuestas valen como ideológicas pero carecen del menor atisbo crítico. Digamos, por insistir en el símil de la costura, que son vestimentas desmedidas, capaces, apenas, de encubrir - no dejar ver - el objeto al que abordan.

La crítica histórica encontrará obstáculos cuando una literatura hecha por nativos de un terruño determinado esté escrita en más de un idioma, de modo que la asimilación entre nación y lengua quede en entredicho. 0 , al revés, cuando una misma lengua sirva de soporte y referencia a literaturas de diversos Estados o naciones. La costurerita deberá distinguir entre vestido y disfraz, uno de los mayores desafíos de su oficio.

\section{3}

15 ¿Es posible una crítica científica ? El intento se ha propuesto varias veces. En el siglo XIX, el positivismo consagró como único conocimiento válido el de las ciencias naturales, cuyo paradigma era, para Comte, la astronomía, abarcante de las matemáticas, la física y la química. De tal modo, los positivistas se acercaron a la literatura con herramientas de la sociología - física y química social -, la antropología racial, las leyes de la herencia y sus exigencias experimentales. Una novela era como un experimento de laboratorio donde se reproducían las fuerzas actuantes en la naturaleza. Ciertamente, todo escritor es un sujeto dotado de realidad física y química, portador de herencias genéticas, sometido a la influencia astral y - en caso de admitirse su existencia - perteneciente a alguna raza. Pero, en tal caso, nadie podría leer un poema sin haber cursado antes varias carreras pertinentes, lo cual tornaría imposible el trabajo de la costurerita.

años treinta del pasado siglo y en Alemania, se mantuvo esta epistemología, aunque reducida al campo específico que nos interesa. Se creó una ciencia de la literatura. Y en los años sesenta, el auge del formalismo ruso y el estructuralismo de Praga y París volvió a sostenerse en parecidos principios. No niego la utilidad del procedimiento mas observo las mismas limitaciones que en los anteriores ejemplos. Un texto cualquiera, literario o no - recordemos el fervor estructuralista por los anuncios de productos alimenticios y las descripciones que acompañan a los figurines de moda - es una estructura : un campo de signos que tiene límites formales y cuyos elementos se significan gracias a las relaciones internas que mantienen. De ahí a filosofar sobre qué hace alguien que lee, hay una distancia epistemológica notable. Hoy no faltan quienes amplían el panorama y consideran literario a cualquier acto de lenguaje, por ejemplo la guía de teléfonos, cosa que a los estructuralistas clásicos les parecería una aberración, ocupados como estuvieron por la literaturiedad, por lo literario en sí.

Estas posturas caen en ciertos errores de concepto que equivalen a los pinchazos de la costurerita cuando se cose los dedos en vez de coser la tela. Uno es que, al cientifizar el objeto, lo inmovilizan y lo abstraen, destruyendo su carácter fluyente, variable e inestable. Suponen que el hecho de que una obra cuente con la estabilidad de sus signos escritos le otorga un carácter estable. Obvian así la diversidad de lecturas que cualquier 
texto soporta. Diría más : que exige. Basta recorrer la historia de las lecturas que arrastra cualquier clásico para comprobarlo. Son todas válidas aunque no sean todas igualmente convincentes. Incluyo los momentos de silencio, los tiempos en que ciertos libros dejan de leerse como si nunca hubieran existido. $O$ los sacudones que hacen de una obra maestra un modelo de incorrecciones y viceversa. Vale recordar lo que se ha dicho y callado respecto a Cervantes y Shakespeare.

Otro error de las pretensiones cientificistas consiste en no calibrar la calidad del lenguaje literario, su carácter ambiguo $\mathrm{y}$, por lo tanto, abierto y concreto, como lo señaló oportunamente Umberto Eco en plena batahola estructural. La apelación a las ciencias del lenguaje como las más desarrolladas de las llamadas ciencias humanas, siguiendo el magisterio de Lévi Strauss y el uso que él hace de la lingüística racionalista saussuriana, no lo impide. ¿Quién ha hecho más literatura que el autor de Tristes trópicos y Lo crudo y lo cocido ? El mismo Barthes, que conoció a Saussure gracias a Greimas, acaba construyendo una suerte de lingüística de la significación, donde valen los signos tanto como los símbolos y los meros indicios. De algún modo, su análisis párrafo a párrafo de Sarrazine de Balzac, es una reducción al absurdo de toda pretensión analítico-científica, ya que el texto del comentario excede al texto comentado. ¿Alguien puede imaginarse a Proust sometido a semejante culto de la minucia? No, desde luego, a Barthes escribiendo sobre Proust.

Ciertamente, hay una doctrina del acto poético cercana - pero nada confundible - a este campo, el simbolismo mallarmeano. Poético es el lenguaje producido por un sujeto que se borra a favor de la iniciativa que cede a las palabras. Se borra y se reconstituye, en un vínculo dialéctico con ellas. Digamos que un poeta no sale del poema tal como entró. Antes, además, porque ha habido un sujeto que decidió ponerse entre paréntesis y someterse a la sugestión verbal. Nada digamos de lo que llega al lector, resultado de correcciones que, en definitiva, son censuras formalizantes.

Si propusiéramos a Mallarmé una figura afín a la costura, seguramente diría que la costurerita cose la camisa del hombre feliz, que anda a pecho descubierto, en verano y en invierno. O Lacan, que prefiere la dualidad entre el Je (el que somos ante los demás) y el Moi (el que imaginamos ser), siempre teniendo en cuenta que el lenguaje es un elemento de alteridad porque nos lo han impuesto los otros o lo aprendemos libremente de los otros, en tanto lengua constituida de antemano por ellos.

21 Esta alteridad nos lleva a la cuestión de la autonomía de la obra literaria, que se ejerce cuando el lenguaje excede su tarea meramente comunicativa, la que estudia la lingüística. Todas las palabras que usa un escritor, incluidas las que inventa, pertenecen al código de la lengua pero sus textos no están en él. Por otro lado la literatura es autónoma pero no es autárquica. Lo sería si estuviera escrita en una lengua totalmente inventada por el escritor, un idiolecto, invulnerable a la lectura de terceros.

Permanece, en cambio, el derecho que los formalistas vindican para el escritor, el ser autotélico, valerse de las palabras para sus propios fines y no simplemente para los fines establecidos en la comunicación social. Si no una lengua, la llamada por Valéry lengua mandarina (cosa de mandarines y no de verduleros), un recorte dentro de la lengua general que permite realizarse como estilo. Estilo, estilete: una herramienta afilada y cortante. La costurerita se vale de hilos y agujas fabricados por otros, pero la puntada lleva la impronta personal de su mano. 
23 Ya que hemos dado con el sujeto, es el turno del psicoanálisis. Para ello propongo recordar lo dicho por Sigmund Freud : "No soy en realidad un científico, un observador, un experimentador ni un pensador: soy un conquistador." De igual manera se puede afirmar que el crítico no demuestra verdades científicas, ni es un mero espectador ni un perseguidor de apotegmas filosóficos sino que conquista el texto, se adueña de él como todo lector. Con ínfulas de monarca absoluto, como el Papa de Roma. Lo digo porque los reyes de hoy son todos constitucionales.

Visto desde el taller de costura, Freud podría definirse como una costurera que compone un vestido con restos de otros varios, haciendo una suerte de patchwork, de remiendos ingeniosos que devuelven al traje la unidad perdida por el uso, es decir por el juego de la memoria y el olvido. Debajo de la ropa, late el cuerpo. El propio Freud, un judío criado por una niñera checa, se vio tentado por la poligrafía. Escribió en alemán, algunos diarios de juventud en griego, estudió en francés con Charcot y aprendió el español para leer a Cervantes y el inglés para hacerlo con Milton y Shakespeare. Aquí, pues, importa el buen hombre como lector. Cabe dejarlo de lado como clínico, ya que leer la escritura en busca de los psiquismos de los personajes y del autor, ambos ficcionalizados por la literatura, es tarea impropia. Freud, leyendo a los escritores que tanto amó y a los cuales concedió tanto crédito, no era un psiquiatra en busca de diagnósticos.

Cabe, entonces, desandar ese camino y ver en Freud a un ensayista alimentado por sus lecturas, por las historias que le importaron. Lo incomodaban "las fastidiosas exactitudes" de la ciencia. Sus modelos fueron Stuart Mill y Platón, un narrador crítico de mitos. En Edipo y Hamlet encontró la horma de algunas categorías decisivas. Así, al ver a Sarah Bernhardt en un melodrama de Sardou, evocó a las histéricas de la Salpetriére y, al repasarlas, revió las actitudes armoniosamente desarticuladas de la gran Sarah. Se inquietó, entonces, por la gramática del cuerpo y la palabra que lo llevó a sus primeros estudios sobre la histeria, que tenía su propia retórica. Retorizar es convencer y convencer - cuando no directamente, seducir - es cosa del arte. En sus sesiones, recibía los andrajos de vestiduras deshechas que él, como buena costurera, debía recoser.

Sus primerizos Estudios sobre la histeria fueron mal recibidos por los clínicos y, en cambio, los elogió Alfred von Bergner, un profesor de historia de la literatura y director del Teatro Imperial de Viena. Lo precisó: es un cirujano del alma. Cirujano: quien, como una costurera, remienda las heridas quirúrgicas. A Kraft Ebbing, sexólogo, le pareció un narrador de cuentos de hadas en clave de lenguaje científico. ¿Todo un elogio ? Digo que sí, a pesar de quien lo dijera.

27 En el autonálisis, el investigador se desdobla como un narrador : lector y escritor a la vez. La infancia se reconstruye como relato. No tenemos pasado, llegamos a tenerlo: Marcel Proust, un novelista para quien escribir es internarse en la exploración de una lengua bárbara, traducir. El histérico, por las suyas, es a menudo un narrador de traumas fantásticos. Por ellos se puede llegar a la metapsicología, cuyo material de trabajo es la filosofía, la curiosidad por saber, el amor al saber propio del artista. Es problemático y es ideal, ahí te las den todas.

En otros campos, a Freud le interesaron las formas de decir, que son las que sirven para resolver un texto. Los actos fallidos, que son los más expresivos y significantes. El Witz, 
palabra intraducible que puede querer decir un chiste que se ocupa de lo más serio enmascarándose de amabilidad risueña, como asimismo lo que la palabra nos dice por sí misma cuando queremos hacerle decir lo que queremos que diga. Toda la poética contemporánea, desde Mallarmé, Rubén Darío y Huidobro, proviene de ese hallazgo.

Freud, al revés de la psiquiatría, que quiere curar lo anómalo convirtiéndolo en normal, se interesa por el poder creativo de las anomalías. Un escritor es benéficamente obsesivo : sus temas son irreductibles obsesiones. La neurosis es necesaria para constituir al sujeto, en la tensión entre sus impulsos y las hormas impuestas por la cultura, el lenguaje en primer lugar. En la invención literaria, el escritor explora su nativa bisexualidad, lo dúplice y enmascarado de su identidad, y los despliega en sus poblaciones de figuras y personajes. Flaubert es Madame Bovary y Tolstói es Anna Karenina. En la interpretación de los sueños, el analista relee un cuento que el paciente le hace, vigil, de lo que recuerda, olvida y fantasea de lo que ha soñado. Hasta es posible ver en quien escribe a un paranoico que es exigido por un fantasma a dar explicaciones, a volverse explícito en un texto que conocerá el público, los desconocidos que acechan con apetito lo que él deja escribiendo. Hasta es posible ver en los sistemas filosóficos y las sagas novelísticas o dramáticas un intento del perseguido por cerrar su espacio y blindarlo. Inútil : el lector lo abrirá por su cuenta. La costurerita es una exploradora de dobladillos y entretelas. Todo tapiz tiene su envés.

\section{5}

Como se ve, los utillajes críticos son muy variados. Hubo un tiempo en que polemizaron para ver quién tenía la única razón crítica. En estos años las cosas se han remansado y tendemos a una buena convivencia sintética, cuando no a un mal eclecticismo. No se trata de rehacer un viejo vestido sino de coser uno nuevo y durable, donde se integren antiguas disidencias. Acaso la olvidada estilística señale un posible camino de encuentro.

Hoy sus maestros son paladines del olvido, como Leo Spitzer y Karl Vössler. Lo mismo en cuanto a los filósofos afines (Benedetto Croce) y los maestros de los profesores, MeyerLübcke y Hugo Schuchardt. No los recuerdo citados en los últimos cuarenta años, durante los cuales han caducado, en cambio, con o sin justicia, eso que el tango llama "milongueras pretensiones". Existió, en la posguerra, una versión simplona y banal de la estilística en algunos ensayistas celtibéricos, que Octavio Paz calificó de pedregosos y arenosos. 0 sea que mejor habría sido evitarlos.

Quizás estas amnesias tengan que ver con algo que vengo insinuando sin explicitarlo, lo que la costurerita llamaría sus moldes en papel manteca, el cañamazo del bordado, el telar del tapiz. Toda crítica ha de ser autocrítica, capaz de ponerse en crisis y por ello, remitirse a alguna filosofía. Por ejemplo : la escuela histórica se soporta en una filosofía de la historia cuyos sujetos son los pueblos; los formalismos y estructuralismos, en una noción del texto como estable y dotado de positiva realidad; el sociologismo, en una lectura materialista de la historia, es decir de la historia como materia de sí misma; el psicoanálisis, en una filosofía del lenguaje que ve en el signo verbal algo sospechoso de ocultamiento pero no lo ataca como quien revela o desenmascara sino que estudia el camino o procedimiento que lleva de lo expuesto a lo negado.

Diría que la estilística y sus meditaciones poéticas afines - las provenientes, lo dije, del simbolismo - apuntan a una filosofía del lenguaje que admite, al menos, dos niveles del 
mismo : uno comunicacional, materia de la lingüística y que propende a la cerrazón del código de la lengua; y otro poético, que no deroga dicho código pero lo abre, lo resquebraja, lo tijeretea como la costurerita cuando secciona el paño que viene arrollado al carretel. ¿Los malos pasos que menciona el poema de Carriego ?

Es cierto que hay un código de la lengua que pretende cubrir todas sus contingencias, o sea el habla y la literatura. Pero no es menos cierto que las dos se ocupan de obedecerlo y de violarlo, a veces con idiotismos y otras con neologismos y significaciones metafóricas o metonímicas que resultan creativas de lenguaje y que el código, aun a regañadientes, tendrá que incorporar. Son actos de lenguaje de los que no se puede discurrir pero que hacen discurrir, que no se pueden razonar pero no son inmunes a la razón porque están formulados con elementos de lengua razonables. Cuando Rilke dice "Todo ángel es terrible" no dice algo que pueda demostrarse discursivamente como la electrolisis del agua, llegando a la conclusión de que es un compuesto de hidrógeno y oxígeno. Sin embargo, hará discurrir durante años y acaso siglos, a sus lectores a partir de su corrección gramatical y sintáctica.

Entonces : a la fijeza del signo corresponde la inestabilidad de su desciframiento, si es que el signo es poético. Se debe a esa doble condición enigmática - es histórico, como tal pertenece a un momento del pasado, y es actual, pertenece a cada momento de cada recepción por parte de cada receptor - y al hecho de que el lenguaje tiene instantes de poeticidad, si se excusa esta pedantería, en que abusa de sí mismo. Esto le puede ocurrir al más letrado de los letrados o puede aparecer en la poesía popular, donde intervienen poetas iletrados y anónimos. Y hasta en el habla cotidiana. Una vecina elogió a otra, en el patio de luces de mi casa, llamándola "maja" y la otra, empujada por la pulsión de la rima, mejoró la alabanza, llamándola "alhaja". Ahí queda eso, que si no lo escribo se olvida. Nadie sabe cómo se llamaba la costurerita que inventó el nudo para ajustar botones de camisa.

Entonces : la literatura suele apelar a voces que se desvían del uso convenido del lenguaje, que son como disonancias en una partitura y que pueden, en sus rachas de felicidad, convertirse en estilo. Ya señalé lo cortante y puntiagudo de la palabrita. Ahora bien : estas cosas se dan porque la inmanencia de las lenguas, sus virtualidades, parecen permitirlo. El poeta, en vez de aceptar las palabras desde la superficie, para sostenerlas entre sus manos como si fueran herramientas, se mete en ellas y explora sus selvas vírgenes. Se puede hablar, si cabe, de expresión, tomando la palabra en su sentido elemental: el acto de exprimir, como quien exprime una naranja o un limón. La literatura es expresiva de las energías potenciales de una lengua - seamos estentóreos : de su genio -, las cuales operan en el interior de algún sujeto, exprimido a su vez hasta que algo sale entre líneas. Es lo que un romántico llamaría expresivo como espontáneo y genuino, acaso porque lo genuino tiene que ver con aquel genio. Toda significación, pues, posee cualidades estilísticas y así es posible que una misma disciplina se ocupe de encontrarlas en acto.

En otro orden, cada una de estas actuaciones se da en una época y cada tiempo ofrece diferencias históricas, habilita recursos para permitir la expresión, censuras, buenas maneras del lenguaje, artimañas suasorias (convictivas), en fin: retóricas. No en el sentido manoseado con que solemos ocuparnos despectivamente de esta palabra, el hablar por hablar o el hablablar sino en el sentido radical de ser una habilidad que involucra al receptor en el emisor por medio de la persuasión. Lo enigmático del arte hace que, formulado en una retórica de determinada época, un mensaje pueda producir una emoción en otra época, de modo que hay una doble potencialidad en él : la retórica que 
pertenece a su tiempo genético y la estética, que posee la cualidad de recaer en el tiempo y cobrar una actualidad intemporal, es decir capaz de resituarse en el mismo tiempo. 0 , si somos de nuevo estentóreos: porque nos dice algo que es eterno, en sí mismo impronunciable.

¿Por qué esta dialéctica entre lo temporal como pasaje y lo temporal como actuación ? Los maestros de la estilística lo atribuyen a un desajuste entre las palabras, escasas, y el mundo de las cosas, inabarcable y, por lo mismo, inefable. Lo que realmente queremos significar no podemos nombrarlo del todo y por eso intentamos nombrarlo de incontables modos : lenguas, dialectos, idiolectos, estilos, personalismos, suma y sigue. Si nuestras palabras pudieran nombrarlo todo y para siempre, no habría poesía. Toda palabra dice pero, en tanto orden del sentido, dice en suspenso.

Vale la pena pensar o imaginar o fantasear si el lenguaje no empezó siendo poético y llegó a ser semántico, si primero fue la metáfora y después vino el significado, si hemos ido y seguimos yendo de lo concreto a lo abstracto para seguir hallando concreciones que resolver y abstracciones que ponen el mundo entre sucesivos paréntesis. ¿La costurerita inventó antes la puntada que el vestido, hasta que advirtió que podía ocuparse del cuerpo ocultándolo y, a la vez, señalándolo con la ropa?

Para conocer hay que involucrarse en una práctica - la costura, por ejemplo - que, fatalmente, altera la realidad, para que siga siendo la misma realidad y una realidad distinta, una y la otra. Un aforismo chino de la última dinastía, formulado por un pensador anónimo y traducido por un traductor igualmente anónimo, dice algo que Hegel repetirá inopinadamente siglos más tarde : para conocer el sabor de una pera, hay que comérsela, o sea destruirla y transformarla, que es un modo secundario de conservarla. $Y$ así el mundo, empezando por la letra, que se aprende por la boca, órgano de la alimentación. Nietzsche dice que nada simboliza mejor el funcionamiento del espíritu que el funcionamiento del estómago. Leer es masticar, destrozar, deglutir, dar paso a la química de la digestión, nutrirse de lo memorable, evacuar lo olvidable. Un vaivén entre mismidad y alteridad, como lo que hace la costurerita cuando cose la camisa del hombre feliz, que no usa camisas. ¿Conseguirá vestirlo sin que pierda su cuerpo ?

\section{RESÚMENES}

Recorrido ensayístico en cinco capítulos sobre la índole y las tareas de la crítica. Se parte de la lectura y se señala el lugar particular ocupado por el crítico. Se señalan las carencias y dificultades de diferentes escuelas teóricas y los aciertos de la estética de la recepción. La cuestión del carácter científico de la crítica atraviesa los dos últimos siglos dando lugar a una serie de enfoques homogéneos que provienen del campo de las ciencias humanas, mientras que a la inversa los últimos años se caracterizan por el abandono de un marco unitario. El autor propone la posibilidad de que la estilística sea uno de los caminos epistemológicos más pertinentes de cara al futuro, porque ella se sustenta en una filosofía del lenguaje que reconoce la esencial inestabilidad de los signos y lo enigmático de los procesos de significación. 
Cet essai évoque en cinq sous-chapitres la nature et l'histoire de la critique littéraire. L'auteur part de la notion de lecture et définit la place du critique. Il passe en revue les carences et les difficultés de plusieurs écoles théoriques ainsi que les réussites de l'esthétique de la réception. Le problème de la scientificité de la critique traverse les deux siècles derniers et des exégèses inspirées par les sciences humaines; dans les dernières années en revanche on voit l'abandon de tout courant unitaire. L'auteur défend l'idée que la stylistique pourrait fournir à nouveau un cadre épistémologique pertinent, car elle s'enracine dans une philosophie du langage qui reconnaît l'instabilité foncière des signes et la nature énigmatique des processus de signification.

The essay evokes the nature and history of literary criticism in five sections. The author reviews first the concept of reading and defines the place of the critic. Then, he comments the weaknesses of different theoretical schools as well as the successes of the esthetics of reception. The problem of the scientific nature of criticism underlies the last two centuries as well as the hermeneutics inspired by human sciences; the last years, nevertheless, show a disappearance of any unitary trend. The author proposes that stylistics may deliver again a relevant epistemic frame given that it emanates from a philosophy of language that predicates the signs instability and the enigmatic nature of meaning.

\section{ÍNDICE}

Mots-clés: Critique, lecture, écoles théoriques, épistémologie littéraire, stylistique

Keywords: Criticism, reading, theoretical schools, literary epistemic, stylistics

Palabras claves: Crítica, lectura, escuelas teóricas, epistemología literaria, estilística

\section{AUTOR}

\section{BLAS MATAMORO}

Ensayista y escritor. Ex-director de Cuadernos Hispanoamericanos 